\title{
COMPARISON OF THE ANTIPROLIFERATIVE ACTIVITY OF DIFFERENT EXTRACTS FROM POTHOMORPHE UMBELLATA IN BREAST CANCER CELL LINES
}

Douglas C. Brandão, Raquel P. Cruz¹, Paula M. A. P. Lima1, Antonielle O. Cordeiro,2, Luiz R. Goulart², Matheus C. Gazolla ${ }^{3}$, Ademar A. S. Filho ${ }^{3}$, Thaise G. de Araújo',

'Laboratory of Genetics and Biotechnology, Institute of Biotechnology, Universidade Federal de Uberlândia - Patos de Minas (MG), Brazil.

'Laboratory of Nanobiotechnology, Institute of Genetics and Biochemistry, Universidade Federal de Uberlândia Uberlândia (MG), Brazil.

${ }^{3}$ School of Pharmacy, Universidade Federal de Juiz de Fora - Juiz de Fora (MG), Brazil.

Breast Cancer (BC) is the second most common cancer type in women. The search for natural products has become increasingly important and promising in oncology. The aim of this study was to evaluate the in vitro cytotoxic potential of hexanic, chloroformic and hydromethanolic extracts from Pothomorphe umbellata, and to compare their antiproliferative activity in the mammary cell lines: MCF10-A (non-tumorigenic control), T47D, MCF-7 and MDA-MB231 (tumoral lineages). The cells were maintained in appropriate culture media according to the recommendations of the ATCC (American Type Culture Collection). The extracts from the aerial parts of $P$. umbellata were used for the treatment of BC cells at different concentrations ( $1 \mathrm{mg} / \mathrm{L}, 0.5 \mathrm{mg} / \mathrm{L}, 0.25 \mathrm{mg} / \mathrm{L}, 0.125 \mathrm{mg} / \mathrm{L}, 0.0625 \mathrm{mg} / \mathrm{L}, 0.03125 \mathrm{mg} / \mathrm{L}, 0.015625 \mathrm{mg} / \mathrm{L}$ and $0.0078125 \mathrm{mg} / \mathrm{L})$ for 24 and 48 hours. The IC50 and selectivity index were calculated. Statistical analyses were performed using GraphPad Prism 8.0 software. We observed a statistically significant decrease of all tumoral lineages proliferation after treatment with all extracts in all concentrations when compared to experimental controls (cells with culture medium alone). In the negative control (DMSO diluent) there were no statistically significant differences. The chloroformic extract from $P$. umbellata was the most effective in antiproliferative capacity. For the MCF-7 cells the IC50 values were: $0.65 \mathrm{mg} / \mathrm{L}$ after treatment with the hexanic extract; $0.16 \mathrm{mg} / \mathrm{L}$ with the chloroformic extract and $0.5 \mathrm{mg} / \mathrm{L}$ with the hydromethanolic extract. For MDA-MB231 it was not possible to calculate the inhibitory concentration. The chloroformic extract was highly selective for the MCF-7 and T47D strains (19.9 and 15.1, respectively). Few studies report the antitumor activity of this species, especially in BC. The results for chloroformic extract are promising for the treatment of luminal tumors, and additional studies are necessary to validate the response of this molecular subtype. 